\title{
METODOLOGIAS VISUAIS E A ANÁLISE DAS IMAGENS SOBRE O CAMPO E A CIDADE NO ENSINO DE GEOGRAFIA - UM ENSAIO EXPERIMENTAL COM A EDUCOPÉDIA
}

\author{
Visual methodologies and the analysis of images of rural and urban at geography teaching: na \\ essay on Educopedia
}

Mendel Aleluia*

* Professor de Geografia no Instituto Federal Fluminense / Doutorando em Geografia na UERJ - maleluia@iff.edu.br.

Recebido em 21/08/2018. Aceito para publicação em 03/09/2018.

Versão online publicada em 20/11/2018 (http://seer.ufrgs.br/paraonde)

\begin{abstract}
Resumo:
Neste trabalho analisamos as atividades da Educopédia naquilo que tange ao tema da relação cidade-campo e sobre os elementos do meio rural. Somando-nos ao conjunto de reflexões sobre a análise do currículo e dos materiais didáticos, buscamos aqui oferecer um enfoque mais específico sobre a questão das imagens. A Educopédia é uma página na internet em que estão disponibilizados um conjunto de aulas para os professores das disciplinas do ensino fundamental na rede municipal do Rio de Janeiro utilizarem na sala de aula. A partir da análise de conteúdos apontamos alguns elementos sobre as imagens e a questão campo-cidade no material didático utilizado.
\end{abstract}

Palavras-chave: Ensino de Geografia; relação campo-cidade; Recursos Didáticos

\begin{abstract}
:
In this article we analyze the activities of Educopedia, when it concerns to the relations between rural and urban. In dialogue with researches of scholar curriculum, our aim is to provide a specific view on the visual content of didactic material. Educopedia is a website where are hosted a huge number of lessons to be used by teachers with the students of basic education in the city of Rio de Janeiro. Using content analysis, we point out some elements about images and the question of rural and urban relations on Educopedia.
\end{abstract}

Key-words: Geography Teaching; Rural and Urban; Didactic Materials

\section{Introdução}

Neste texto temos como objetivo estabelecer, preliminarmente, uma linha de investigação sobre as possibilidades do uso das metodologias visuais descritas por Rose (2001) na análise de materiais didáticos. Neste experimento faremos uso da Educopédia, material editado pela Secretaria Municipal de Educação da Cidade do Rio de Janeiro. Nossa questão específica recai sobre as imagens que retratam campo e cidade nos materiais didáticos, buscando analisar a maneira como tais conteúdos estão presentes na disciplina de Geografia nos anos finais do Ensino Fundamental.

Do ponto de vista teórico nos oferecem suporte os textos de Novaes $(2011 ; 2013)$ e de Rose (2001; 2013). 0 artigo está dividido em três seções: Na primeira apresentamos aspectos sobre as orientações curriculares da rede municipal do Rio de Janeiro. Na segunda discutimos alguns elementos teóricos e de procedimento de análises de material visual. Por fim, apresentamos resultados iniciais da aplicação da 
análise de conteúdos para as imagens sobre a relação campo-cidade na Educopédia.

\section{O tema da pesquisa no currículo e no material didático da PCRJ}

A rede municipal do Rio de Janeiro destaca-se por possuir mais de mil unidades, com um amplo atendimento no ensino fundamental. Nos últimos anos, um conjunto de medidas foram implementadas para a definição e padronização de currículos e materiais didáticos. Para todos os anos do Ensino Fundamental foram reformuladas as Orientações Curriculares, com a constituição de um grupo de especialistas de universidades e professores da rede. Ainda que a maior parte das disciplinas recebam os livros oriundos do Programa Nacional do Livro Didático, foram desenvolvidas apostilas bimestrais com conteúdos e atividades a serem realizadas com as turmas. Há ainda a criação da Educopédia, ferramenta disponível na internet que apresenta aulas e atividades já elaboradas.

Neste artigo, considerando o tema da pesquisa de doutorado em andamento, iremos nos circunscrever as atividades da Educopédia naquilo que tange ao tema da relação cidade-campo e sobre os elementos do meio rural. Somando-nos ao conjunto de reflexões sobre a análise do currículo e dos materiais didáticos, buscamos aqui oferecer um enfoque mais específico sobre a questão das imagens. A visualidade ganha destaque na ferramenta a ser analisada, na medida em que (resguardadas as já conhecidas dificuldades de ordem estrutural nas salas de aula) a possibilidade de projeção de imagens é colocada como recurso importante para a interação entre professores e estudantes ${ }^{1}$.

Para fins de contextualização, julgamos importante destacar alguns elementos das concepções de ensino de geografia presentes nas orientações curriculares que nortearam o material aqui analisado. As Orientações Curriculares de Geografia apresentam-se como complementares a proposta curricular da Multieducação, utilizada pela Prefeitura do Rio de Janeiro desde a década de 1990. Para a disciplina de Geografia, o texto de apresentação traz alguns apontamentos sobre a concepção de ensino da disciplina:

A Geografia, preocupada com os processos que se delineiam no espaço geográfico, se destaca entre as ciências que vêm se empenhando em acompanhar este conjunto de mudanças, discutindo e rediscutindo suas bases teórico-conceituais as quais devem dar conta da apreensão da realidade em sua totalidade. (PREFEITURA DA CIDADE DO RIO DE JANEIRO, 2012, p. 5)

A transposição didática é, para Chevallard (1991), o movimento de construção de um dado objeto de aprendizagem que torne o saber científico ou disciplinar em um saber escolar. Nesse sentido, a preocupação expressa nas orientações curriculares precisa caminhar do campo acadêmico para o conjunto de referenciais do cotidiano dos alunos para que este ganhe sentido e alguma dimensão de concretude. A contextualização é fundamental para a transposição didática, tendo em vista que a mesma se realizaria de forma plena com o aprendizado em si. Pensando pelo ponto de vista da geografia escolar, as referências que contenham alguma familiaridade com espaços conhecidos dos estudantes são uma ferramenta importante para tal processo.

Sem expressar um compromisso direto com alguma corrente teórica da geografia, o texto dos PCNs deixa claro que é o conceito de espaço geográfico que ocupa a centralidade desta proposta pedagógica em Geografia. Está exposta ainda a seguinte preocupação:

Procuramos, ainda, dar ênfase aos estudos sobre o Brasil e o Rio de Janeiro, estado e município, como recortes espaciais que aproximam a construção do conhecimento geográfico à realidade do aluno. (PREFEITURA DA CIDADE DO RIO DE JANEIRO, 2012, p. 5)

\footnotetext{
1 São poucos os registros de sondagens da utilização e da recepção da Educopédia como ferramenta nas escolas. Dolzani (2015), ao apresentar levantamento realizado em duas escolas da rede municipal, aponta que os estudantes consideram a Educopédia como um instrumento interessante e relevante para o andamento das aulas. No entanto, segue sendo necessário que se realizem novos estudos com tal objetivo. Há que se desvendar ainda como é a utilização por parte dos estudantes, não somente tratar de suas opiniões sobre o material.
}

Para0nde!?, Porto Alegre, v.10, n.2, p.156-162, 2018. Edição Especial com artigos publicados originalmente na XII ENANPEGE http://seer.ufrgs.br/paraonde 
O entendimento do papel do currículo é um ponto importante para as pesquisas que querem abordar como um dado tema está presente em uma disciplina escolar. Não podemos nos afastar do caráter político do currículo. Apple $(1990 ; 2000)$ apresenta vínculos estreitos entre currículos e ideologias dominantes, principalmente ao abordar a ascensão de grupos educacionais de direita na educação estadunidense, em que proliferam medidas meritocráticas e de tensionamento político referendando medidas alinhadas com a agenda do neoliberalismo para a educação ${ }^{2}$. Moreira e Silva (1995) consideram que o currículo expressa um projeto político-cultural que abrange tanto o projeto em si, como as práticas que garantem a sua efetivação.

A ideia da construção do conhecimento em Geografia considerando a realidade mais próxima ou mais perceptível aos estudantes é um pressuposto importante e defendido por diferentes autores da área (Castellar e Moraes, 2011; Kimura (2008) e Pontschuka et alli (2007). No entanto, as orientações curriculares do $7^{\circ}$ ano do ensino fundamental, recorte da nossa pesquisa em termos de conteúdo a ser analisado, não fazem referência ao processo de urbanização da cidade do Rio de Janeiro. Neste tema como habilidades a desenvolver o material elenca:

-Conhecer as inter-relações do espaço agrário com o urbano e vice-versa.

-Entender as principais mudanças ocorridas nos espaços agrário e urbano, com o advento das novas tecnologias.

-Inferir a relação de complementação existente entre o campo e a cidade.

0 texto das orientações curriculares também apresenta alguns exemplos de atividades a serem realizadas junto aos alunos. Na temática que estamos analisando surgem as seguintes propostas:

-Montar dois painéis com notícias. Um sobre atividades agrárias e seus problemas e outro sobre as atividades urbanas e seus problemas.

-Promover um debate com os estudantes sobre o desenvolvimento urbano e rural brasileiro, dos anos 1990 até hoje e a participação dos cidadãos neste processo.

-Fazer uma redação sobre as diferenças entre cidade e campo e sobre a exploração sustentável dos seus recursos.

A despeito das potencialidades das atividades propostas, nos chama atenção a ausência de uma menção direta ao uso de imagens, recurso que é estimulado com o lançamento de plataformas como a Educopédia.

\section{3- Sobre imagens e geografia: em busca de parâmetros}

$\mathrm{Na}$ trajetória de pesquisa que buscamos perseguir, torna-se tarefa fundamental deixar de considerar as imagens como mero apêndice dos textos. É imprescindível posicionar o universo de imagens a ser analisado como elementos que, ainda que não tenham uma certa "autonomia" dos outros elementos da realidade, demandam ferramentas de análise específicas. Rose (2001) é uma autora basilar para o objetivo aqui exposto. 0 seu alerta inicial oferece uma linha de pensamento sobre as imagens que nos parece acertado e recomendável: ao pesquisar sobre imagens, a tarefa maior é interpretá-las. Tão somente. Não se trata de "descobrir a verdade" por trás das imagens. Ao mesmo tempo, não pode ser desprezado o contexto no qual determinado elemento visual é reproduzido e difundido. Diante disso, coloca-se um desafio: considerar as imagens em seu contexto sem transformálas em objeto de desvelamento, mas sim discutindo as linguagens em que elas se apresentam, seus usos e também os padrões possíveis de serem identificados.

Um outro risco a ser evitado nos é recordado por Novaes (2013) ${ }^{3}$ : o uso seletivo de determinadas imagens para referendar uma tese pré-concebida. Este recorrente artifício coloca as imagens numa condição de não serem interpretadas por si só e sim como uma evidência de simples corroboração de conclusões pré-formuladas. Não estamos imunes a tais tentações. A seleção das imagens no instrumento de pesquisa que utilizaremos já é em si um processo que evidencia uma escolha anterior. Ainda que a discricionariedade dos processos de escolha seja inevitável, o rigor metodológico

\footnotetext{
2 É o que afirma, por exemplo, Ravitch (2011)

${ }^{3}$ Incorporando contribuições de GINZBURG (1989).
}

Para0nde!?, Porto Alegre, v.10, n.2, p.156-162, 2018. Edição Especial com artigos publicados originalmente na XII ENANPEGE http://seer.ufrgs.br/paraonde 
possibilita uma maior profundidade na análise das imagens em si. Nesta busca, o encontro com o texto de Rose (2001) proveu um guia metodológico com elementos importantes para a análise que demandamos realizar.

Introduzindo o tema das metodologias visuais, Rose (2001) considera que a vida ocidental contemporânea é repleta de referências visuais, incluindo aí o conhecimento científico que cada vez mais se apoia em imagens do que em textos. Em defesa de um approach crítico para a interpretação das imagens a autora apresenta três condições para tal: levar as imagens a sério; refletir sobre os efeitos e as condições sociais dos objetivos visuais; e considerar os vieses existentes no próprio olhar daquele que pesquisa sobre imagens.

Considerando o material aqui analisado e refletindo sobre suas implicações no ensino de Geografia, reverberamos a questão colocada por Novaes (2011):

a constatação desta permanente relação entre geografia e imagem também pode conduzir a um novo questionamento: até que ponto o reconhecimento de que as imagens são importantes no discurso do geógrafo tem resultado em uma reflexão sistemática sobre a representação pictórica na disciplina? (NOVAES, 2011, p. 10)

Sem a pretensão de respondê-la neste breve ensaio, é com este questionamento que buscaremos experimentar algumas possibilidades de análises das imagens contidas na Educopédia.

\section{0 campo na Educopédia: um esboço de análise}

A Educopédia (www.educopedia.com.br) trata-se de uma página na internet em que estão disponibilizados um conjunto de aulas para os professores. Extraímos para análise alguns trechos. A primeira aula sobre o tema chama-se "Espaço Agrário e Urbano: conceituações e diferenças". A apresentação inicial utiliza uma estratégia bastante recorrente que é a de utilizar a paisagem como aproximação inicial. Desta forma fica implicitamente assinalada a importância do uso das imagens no material destinado aos estudantes do 7o $^{\mathbf{0}}$ ano de escolaridade.

Selecionamos um grupo de imagens e discutimos aqui as possibilidades de interpretação de acordo com as metodologias propostas por Rose (2001). Como já ressalto, a proposta aqui é realizar experimentos. Portanto há um certo grau de aleatoriedade na correlação entre metodologias e imagens. As metodologias apresentadas pela autora são: análise composicional; análise de conteúdo; semiologia; psicanálise e análise de discurso. Há ainda um capítulo dedicado a possibilidade de usar métodos mistos.

Dentre as metodologias apresentadas pela autora, nos circunscrevemos aqui à análise de conteúdo. Esta costuma ser aplicada a textos (Kripendorf, 1980). A quantificação das frequências com que determinado elemento aparece é um dado estruturante para a análise de conteúdo. Rose (2001) considera o trabalho de Lutz e Collins (1993) como um importante exemplo das técnicas de análise de conteúdo com imagens. ${ }^{4}$ Rose (2001) propõe um roteiro de quatro passos para a realização da análise de conteúdo: seleção de imagens apropriadas para responder a questão colocada; categorizar as imagens selecionadas; codificar as imagens; e analisar os resultados.

A própria autora apresenta uma ressalva: a análise de conteúdo, ainda que seja uma metodologia que permita desdobramentos razoavelmente objetivos, apresenta como limite o fato de trabalhar apenas com a dimensão composicional, não abordando as questões da produção e da audiência. Neste texto nos permitimos fazer uma breve experiência com um grupo de 23 imagens das aulas da Educopédia no 7ํano do ensino fundamental. Delimitado o universo de imagens passamos ao exercício de categorizá-las. Neste ponto, Rose (2001) afirma que as categorias precisam ser exaustivas, exclusivas e esclarecedoras. Devem, portanto, apresentar definições claras, não permitir o enquadramento em mais de uma delas e servir como pontos para uma análise coerente e reveladora da questão inicial proposta. Seguindo tais pressupostos encaminhamos as categorias que se seguem. Aqui, dados os limitantes de espaço, ilustraremos cada categoria com apenas uma das imagens do grupo de ilustrações da

\footnotetext{
4 Os autores realizaram pesquisa em três décadas de números da revista National Geographic, apresentando análise de conteúdo das imagens da publicação.
}

Para0nde!?, Porto Alegre, v.10, n.2, p.156-162, 2018. Edição Especial com artigos publicados originalmente na XII ENANPEGE http://seer.ufrgs.br/paraonde 
Educopédia.

- Charge retratando elementos do meio rural;

0 recurso à charge e à caricatura, frequentemente encontrado em materiais didáticos, registra na nossa amostra 5 imagens. Como exemplo, trazemos esta que pede uma atividade sobre os movimentos sociais do campo.

\begin{tabular}{|c|}
\hline Observe a \\
charge, reflita \\
e escreva em \\
seu caderno \\
sua opinião. \\
\hline
\end{tabular}

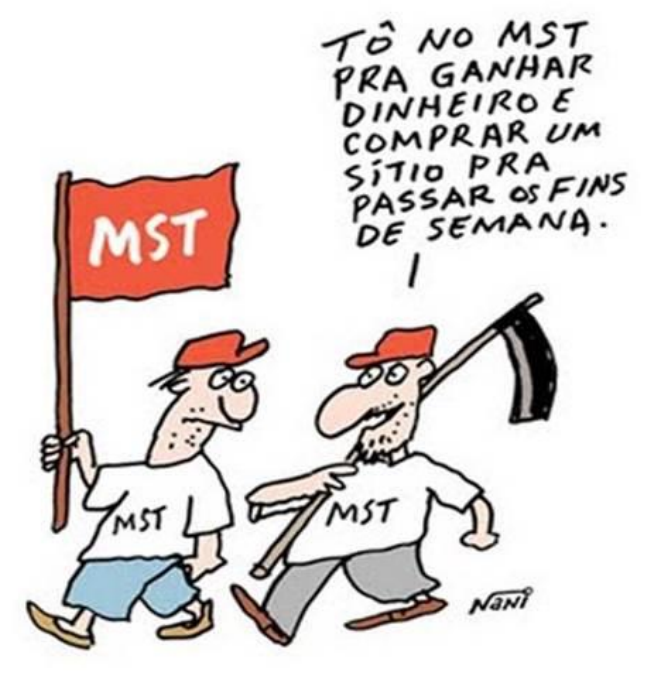

Figura 1 - Charge presente na aula sobre movimentos sociais no campo

- Fotografia retratando elementos do meio rural;

Já as fotografias em que elementos e paisagens vinculadas ao meio rural são apresentados representam 11 imagens. Estas retratam, majoritariamente, ambientes idílicos ou estruturas produtivas vinculadas ao agronegócio.

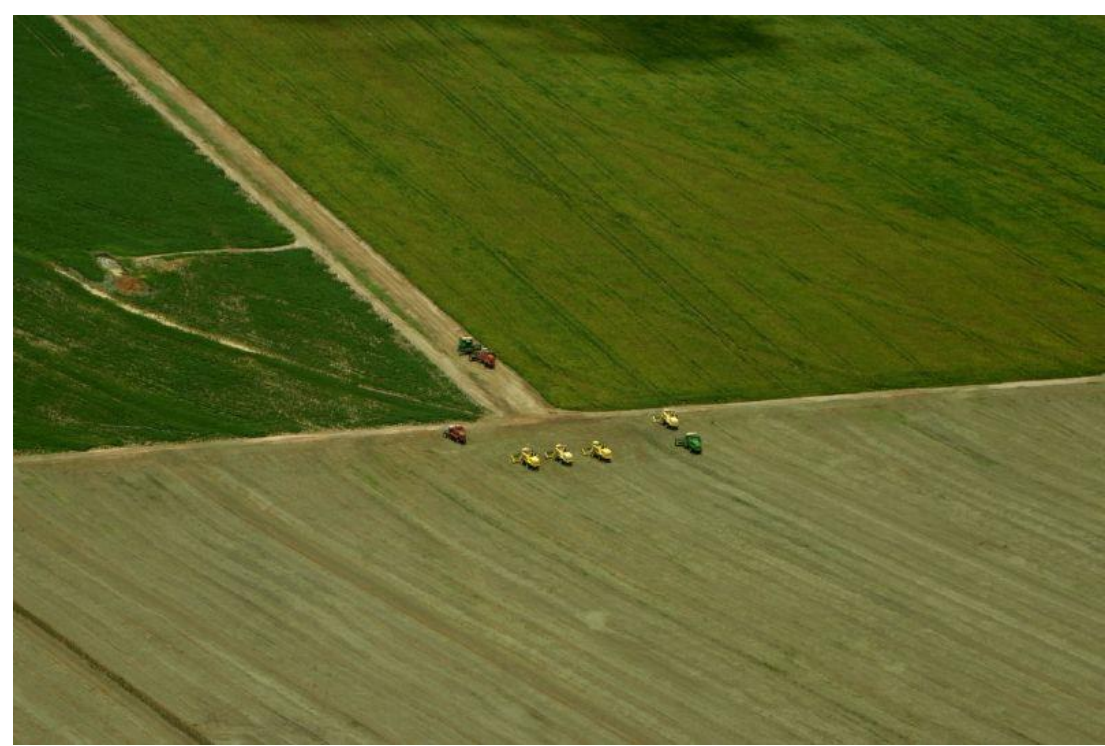

Figura 2 - Fotografia aérea em aula de apresentação sobre o campo

- Charge retratando elementos do meio urbano;

Apenas uma das ilustrações sobre o meio urbano trata das cidades. Está correlacionada com uma imagem sobre o campo, fazendo uma associação com o processo do êxodo rural. 


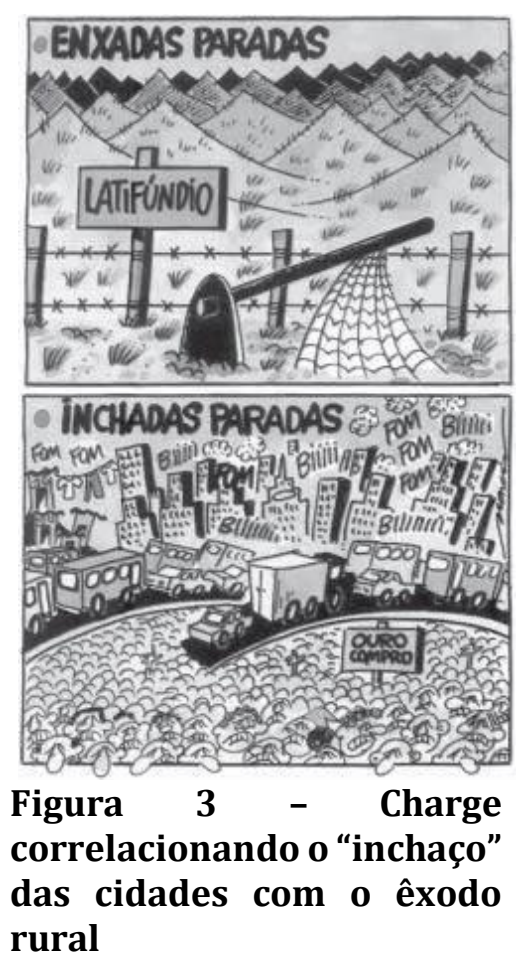

- Fotografia retratando elementos do meio urbano;

São 3 registros de ilustrações relacionadas a espaços urbanos na forma de fotografias. Estas oscilam entre fotografias aéreas e imagens que retratam circulação de pessoas nas cidades.

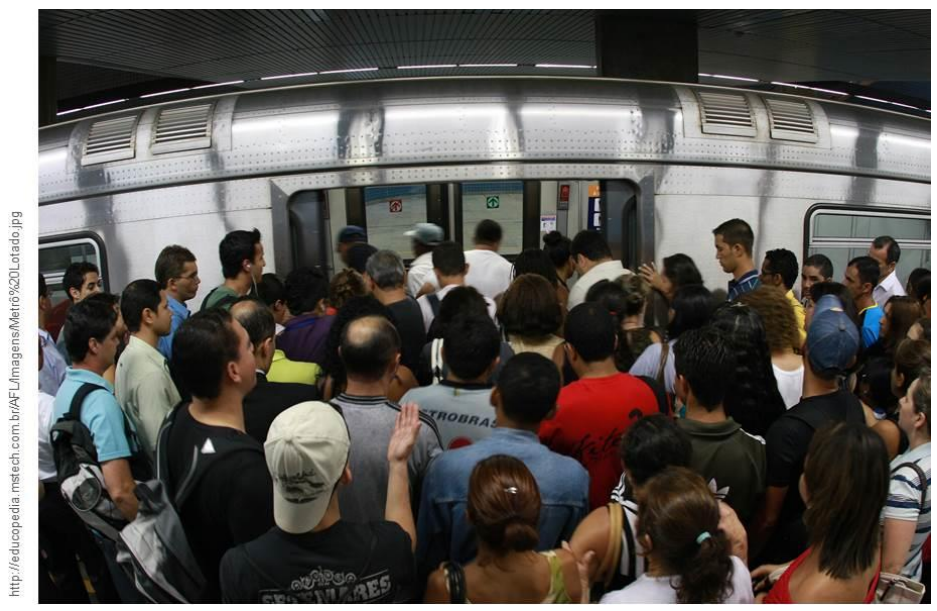

Figura 4 - Deslocamento de pessoas no transporte público apontado como elemento urbano

As imagens analisadas reforçam a suspeita inicial de que o campo aparece de forma mais estereotipada e com menor destaque para a pluralidade de elementos do meio rural. A presença maior de charges pode indicar também a disseminação de ideias pré-concebidas pelos autores do material, vide a questão apresentada sobre o MST. Não negamos que as imagens de cidade exibidas no material também possam ser enquadradas como estereótipos. A pluralidade de representações possíveis do urbano não vai permitir, por si só, apontar qual é a mais legítima. No entanto, ao fazermos o exercício de codificação e posterior análise, nos saltam os olhos a riqueza de elementos registrados na fotografia do urbano, fato que não acontece com o rural, mesmo que este tenha um maior número de imagens registradas. 


\section{Considerações Finais}

A abordagem inicial proposta neste artigo não significa a impossibilidade de analisar seus resultados, ainda que os limites das análises preliminares que fizemos neste ensaio já tenham sido demarcados. É com eventuais possibilidades e passos futuros que nos ocupamos nesta breve seção final. 0 recorte temático que aqui apresentamos pode apresentar alguma resposta para a ponderação de Rose (2013): o equívoco em, ao reconhecer a importância do "visual" na geografia, pensar que somos automaticamente dotados de um aparato teórico e metodológico para trabalhar com ele. 0 "guia" metodológico oferecido pela autora (2001) é caminho interessante para uma reflexão crítica sobre a visualidade na pesquisa em geografia.

0 debate sobre o ensino de geografia é frequentemente marcado por reflexões sobre a transposição didática de determinados conteúdos da geografia acadêmica para a escola. Não escapamos (e nem queremos) totalmente deste movimento. Mas, incorporando as observações de Novaes (2011), vislumbramos a possibilidade do debate sobre a visualidade no ensino da Geografia contribuir para que a própria Geografia acadêmica ofereça novas leituras e debates sobre a questão.

\section{6. $\quad$ Referências}

APPLE, Michael. Ideology and Curriculum. New York: Routledge, 1990

CASTELLAR, Sonia Maria Vanzella e MORAES, Jerusa. Ensino de Geografia. São Paulo: Thompson, 2010

CHEVALLARD, Y. La transposición didáctica: del saber sabio al saber enseñado. Buenos Aires: Aique Grupo Editor, 1991.

DOLZANI, Mirian. Avaliação de Impacto da Plataforma Educopedia na Educação Pública: Uma visão dos alunos. In: Khóra Revista Transdisciplinar, V. 2. 2015

KIMURA, Shoko. Geografia no Ensino Básico. São Paulo: Contexto, 2008

KRIPPENDORF, K. (1980) Content Analysis: An Introduction to its Methodologies. London: Sage

LUTZ, C.A. and COLLINS, J.L. (1993) Reading National Geographic. Chicago: University of Chicago Press.

MOREIRA, A. F. B. \& SILVA, T. T. da. (1995). Sociologia e Teoria Crítica do Currículo: uma introdução. In.: Moreira, A. F. B. \& Silva, T. T. da (Org.). Currículo, Cultura e Sociedade. São Paulo: Cortez. p. 7-37.

NOVAES, André Reyes. "Uma geografia visual? Contribuições para o uso das imagens na difusão do conhecimento geográfico" in Espaço e cultura, UERJ, RJ, N. 30, P.6-22, jul./dez de 2011.

NOVAES, André Reyes. Geografia e história da arte: apontamentos para uma crítia à iconologia. Espaço e Cultura: 43-64, 2013.

PONTUSCHKA, Nidia Nacib et alli . Para ensinar e aprender Geografia. 1a. ed. São Paulo: Cortez, 2007

PREFEITURA DA CIDADE DO RIO DE JANEIRO. Orientações Curriculares de Geografia. Rio de Janeiro, 2011

. Caderno de Atividades. 7ํㅡㄹ Ano do Ensino Fundamental. Rio de Janeiro, 2012

ROSE, Gillian. Visual methodologies: an introduction to the interpretation of visual materials, London: SAGE Publications, 2001

ROSE, Gillian. "Sobre a necessidade de se perguntar de que forma, exatamente, a geografia é visual?." Espaço e Cultura: 197-206, 2013

ParaOnde!?, Porto Alegre, v.10, n.2, p.156-162, 2018. Edição Especial com artigos publicados originalmente na XII ENANPEGE http://seer.ufrgs.br/paraonde 